\title{
Congenital vasopressin deficiency and acute and chronic opiate effects on hypothalamo-pituitary-adrenal axis activity in Brattleboro rats
}

\author{
Ágnes Domokos, Zsuzsa Mergl, István Barna, Gábor B Makara and Dóra Zelena \\ Institute of Experimental Medicine, Hungarian Academy of Sciences, Szigony 43, 1083 Budapest, Hungary \\ (Correspondence should be addressed to D Zelena; Email: zelena@koki.hu)
}

\begin{abstract}
A growing body of evidence suggests that vasopressinergic activity in the hypothalamus is important in stress-related behaviors (like drug abuse) in line with a role in the regulation of the hypothalamo-pituitary-adrenal axis (HPA). We hypothesized that in the naturally vasopressin-deficient Brattleboro rat, acute and chronic morphine treatment may lead to reduced HPA axis activity. Rats were treated either with a single dose of morphine (10 $\mathrm{mg} / \mathrm{kg}$ subcutaneously) and serial blood samples were taken or were treated twice daily with increasing doses of morphine $(10-100 \mathrm{mg} / \mathrm{kg}$ subcutaneously) for 16 days and animals were killed by decapitation 4 or $16 \mathrm{~h}$ after the last injection. Single morphine injection induced a biphasic ACTH and corticosterone
\end{abstract}

elevation with smaller increases in vasopressin-deficient rats. Chronic morphine treatment induced the typical somatic and HPA axis changes of chronic stress; the absence of vasopressin did not prevent these changes. In rats repeatedly treated with morphine plasma, ACTH and corticosterone levels were elevated both 4 and $16 \mathrm{~h}$ after the last injection (short and long withdrawal) and the absence of vasopressin attenuated this response. Our data suggest that vasopressin plays a prominent role in morphine treatment and withdrawalinduced acute hormonal changes, but does not affect development of chronic hyperactivity of the HPA axis.

Journal of Endocrinology (2008) 196, 113-121

\section{Introduction}

Drug abuse is an important problem worldwide. Morphine, a drug often used for medical purposes (perioperative analgesia and cancer-related pain), is a commonly abused drug. Their connection with stress is bi-directional: exposure to stress may be related to the use of recreational drugs (Antelman et al. 1980, Deroche et al. 1992, Breese et al. 2004) and the use and/ or more likely the withdrawal of these drugs may induce severe stress symptoms. Stress activates the hypothalamopituitary-adrenal (HPA) axis, a fundamental mechanism of adaptation and survival strategies. Exogenous (e.g., morphine) as well as endogenous opioids ( $\beta$-endorphine and enkephalins) are believed to play an important although complex role in the control of the HPA axis. In rats, acute administration of both morphine and its antagonist, naloxone leads to HPA axis activation (e.g., Briggs \& Munson 1955, Buckingham \& Cooper 1986a). The activation results in a sequence of events: enhanced secretion of corticotropinreleasing hormone $(\mathrm{CRH})$ from the parvocellular cells of the nucleus paraventricularis hypothalami (PVN) into the portal vessels of hypophysis, followed by increased adrenocorticotropin (ACTH) production from its precursor proopiomelanocortin (POMC) in the pituitary gland, and elevated synthesis and release of glucocorticoids (in rodents mainly corticosterone, in humans cortisol) into the general circulation from the adrenal gland. Opiate-induced HPA axis changes appear to be mediated centrally, since some agonist stimulated in vitro $\mathrm{CRH}$ release from the hypothalamus but not the release of ACTH from the pituitary gland (Buckingham 1982, Buckingham \& Cooper 1986b). Chronic administration of morphine may result in tolerance to the stimulatory effect of the opioid on the HPA axis (Buckingham \& Cooper 1984, Ignar \& Kuhn 1990); the secretion of pituitary ACTH in response to (other) stressors may become suppressed (Briggs \& Munsoon 1955, Buckingham \& Cooper 1984). In contrast, chronic intermittent (e.g., twice daily) administration of morphine may lead to chronic stress probably as a consequence of repeated withdrawal (Houshyar et al. 2001a, 2003, Zelena et al. 2005).

In the mammalian brain the nonapeptide, arginine vasopressin (AVP) is predominantly synthesized in magnocellular neurons located within the PVN and supraoptic nuclei of the hypothalamus and acts in the periphery as antidiuretic hormone. In addition to, but independently of, this peripheral secretion AVP is synthesized in parvocellular neurons of the PVN and together with CRH influences the release of ACTH in the anterior lobe of the pituitary gland (Antoni 1993). The role of AVP in HPA axis regulation becomes more pronounced during chronic hyperactivity of the axis (Dallman 1993, Aguilera 1994). Besides expression in the hypothalamus, AVP is also synthetized in several structures 
of the limbic system (e.g., amygdala), where it affects interneuronal communication (Tribollet et al. 1988).

To characterize the role of AVP in physiological processes, the genetically AVP-deficient Brattleboro rat provides a good model. The AVP prohormone is processed into AVP, neurophysin, and a glycoprotein; these processes are disrupted in Brattleboro rats due to a single nucleotide deletion in the neurophysin region of the AVP gene resulting in functional AVP deficiency (Schmale \& Richter 1984). Here, we studied the role of AVP in the HPA activation during acute and repeated morphine treatment in AVP-deficient Brattleboro rats. The hypothesis was that when AVP is involved in acute morphine treatment-induced HPA axis regulation, its absence will result in a less pronounced stress hormone response. We also hypothesized that AVP contributes to the development of chronic stress symptoms (Dallman 1993, Aguilera 1994) and thus a lack of AVP could reduce somatic and HPA axis changes due to chronic morphine treatment.

\section{Materials and Methods}

\section{Animals}

Male Brattleboro rats aged 3-4 months ( 300 g) were bred in our institute from a colony originating from Harlan (Indianapolis, IN, USA). We compared homozygous (di/di) AVP-deficient rats with congenital diabetes insipidus with heterozygous $(\mathrm{di} /+)$ control rats from the same litters. The parent Long Evans strain does not seem to be an appropriate control as they were separated almost 50 years ago and therefore they could differ in other genes (Bohus \& de Wied 1998, Zelena et al. 2003b). Moreover, the genotypes of the mother may influence the results and therefore we preferred to compare littermates (Zelena et al. 2003a). Rats were maintained in a controlled environment (temperature $23 \pm 1{ }^{\circ} \mathrm{C}$, humidity $50-70 \%$, day:night schedule of $12: 12 \mathrm{~h}$, with lights on at $0700 \mathrm{~h}$ ) and were fed commercial rat chow (Charles River, Budapest, Hungary) with free access to tapwater. Due to the extremely high urine production in di/ di rats, their sawdust bedding was changed daily. The animals were isolated at the beginning of experiment (individual cage size: $42.5 \times 26.6 \times 18.5 \mathrm{~cm}, 1291$ Eurostandard Type III/h). All studies were carried out in accordance with the European Community Council Directive of 24 November 1986 (86/ $609 /$ EEC) and were reviewed and approved by the Animal Welfare Committee of the Institute of Experimental Medicine.

\section{Acute morphine treatment}

Anesthesia was induced by i.p. injection of ketamine (50 mg/kg, SelBruHa Állatgyógyászati Kft, Hungary)xylazine $(20 \mathrm{mg} / \mathrm{kg}$, Spofa, Prague, Czech Republic)promethazinium chloratum $(0 \cdot 2 \mathrm{ml} / \mathrm{kg}$, EGIS, Budapest, Hungary). Two days before the experiment, an intra-atrial
Silastic catheter (medical-grade silicone tubing, ID 0·64, OD $1.2 \mathrm{~mm}$, Dow, Corning, MI, USA) was implanted in the right jugular vein for blood sampling. The cannula was tunneled under the skin of the back, closed and connected to a longer extension tube at the beginning of experiment. Blood samples $(0.4 \mathrm{ml})$ were collected before and at 5, 15, 30, 60 , and $90 \mathrm{~min}$ after a single s.c. morphine injection $(10 \mathrm{mg} / \mathrm{kg}$ per $2 \mathrm{ml}$ saline) into ice-cold tubes with $50 \mu \mathrm{l}$ $20 \% \mathrm{~K}_{2}$ EDTA; blood taken was replaced by $0.9 \% \mathrm{NaCl}$. The samples were centrifuged immediately and plasma was stored at $-20{ }^{\circ} \mathrm{C}$ until assayed for hormone content.

\section{Chronic morphine treatment}

On the basis of previous studies (Houshyar et al. 2001a,b), morphine dependency was induced by s.c. injections of morphine (Morphinium chloratum Ph. Eur. 4, ICN, Budapest, Hungary) twice daily at 0700 and $1900 \mathrm{~h}$ for 16 consecutive days (Table 1). During the first 10 days, the dose of morphine was increased by $10 \mathrm{mg} / \mathrm{kg}$ per injection each day from 10 to $100 \mathrm{mg} / \mathrm{kg}$ per injection of morphine. The controls received $0 \cdot 9 \%$ saline $(0 \cdot 2 \mathrm{ml} / 100 \mathrm{~g})$. On the morning of decapitation (at the time of last injection), we took blood from the tail under slight restraint for $<2 \mathrm{~min}$, cutting it with a sharp surgical knife. Half of previously morphine-treated animals got only saline (MS group, longer withdrawal, $16 \mathrm{~h}$ ), while the other half were treated with $100 \mathrm{mg} / \mathrm{kg}$ morphine (MM group, $4 \mathrm{~h}$ 'withdrawal'). As a single $100 \mathrm{mg} / \mathrm{kg}$ morphine injection was lethal to $50 \%$ of naive rats (preliminary results), we decided to leave out this control group. The animals were decapitated $4 \mathrm{~h}$ after the last injection, at around $0011 \mathrm{~h}$. Altogether, six groups from three series ( $n=18-22$ per group) were compared except for weight changes, as we measured the weight of the animals $\sim 24 \mathrm{~h}$ before decapitation to avoid additional handling stress.

From decapitated animals, organ mass (thymus and both adrenal glands) were assessed in pre-weighted tubes and blood was collected into ice-cooled tubes using EDTA as anticoagulant $(7-10 \mathrm{ml}$ blood to $150 \mu \mathrm{l} 20 \mathrm{w} / \mathrm{v}$ EDTA) for hormone measurement by RIA. After decapitation the skull was opened and the brain removed, snap-frozen on dry ice, and stored at $-70{ }^{\circ} \mathrm{C}$ until $\mathrm{CRH}$ and AVP mRNA determination by in situ hybridization. The whole pituitary gland was immediately frozen on dry ice in embedding medium and handled similar to brain until POMC mRNA determination by in situ hybridization.

\section{Hormone measurements}

Plasma ACTH was measured by RIA on $50 \mu$ l unextracted plasma using a specific antiserum developed in the Institute of Experimental Medicine (Zelena et al. 1999). The intra-assay coefficient of variation was $7 \cdot 2 \%$ and all samples from a single experiment were measured in the same RIA. Plasma corticosterone was measured on $10 \mu \mathrm{l}$ unextracted plasma by RIA using a specific antiserum developed in the Institute of Experimental Medicine (Zelena et al. 2003a). The intra-assay 
Table 1 Treatment protocol in experiment 2

$\mathrm{di} /+$ or $\mathrm{di} / \mathrm{di}$

\begin{tabular}{|c|c|c|c|c|c|c|c|c|}
\hline \multicolumn{3}{|c|}{ Control (2 ml/kg) } & \multicolumn{6}{|c|}{ Morphine (mg/kg) } \\
\hline \multicolumn{3}{|c|}{ CC } & \multicolumn{3}{|c|}{ MM } & \multicolumn{3}{|c|}{ MC } \\
\hline $07 \mathrm{~h}$ & $11 \mathrm{~h}$ & $19 \mathrm{~h}$ & $07 \mathrm{~h}$ & $11 \mathrm{~h}$ & $19 \mathrm{~h}$ & $07 \mathrm{~h}$ & $11 \mathrm{~h}$ & $19 \mathrm{~h}$ \\
\hline sal. & & sal. & 10 & & 10 & 10 & & 10 \\
\hline sal. & & sal. & 20 & & 20 & 20 & & 20 \\
\hline$\ldots$ & & $\ldots$ & +10 & & +10 & +10 & & +10 \\
\hline sal. & & sal. & 100 & & 100 & 100 & & 100 \\
\hline sal. & & sal. & 100 & & 100 & 100 & & 100 \\
\hline$\cdots$ & & $\cdots$ & $\ldots$ & & $\ldots$ & $\ldots$ & & $\ldots$ \\
\hline sal. & & sal. & 100 & & 100 & 100 & & 100 \\
\hline $\begin{array}{l}\text { sal. } \\
\text { cort. }\end{array}$ & decap. & & cort. & decap. & & $\begin{array}{l}\text { sal. } \\
\text { cort. }\end{array}$ & decap. & \\
\hline
\end{tabular}

CC group got s.c. saline injections each time. MM group got increasing doses of s.c. morphine. MC group was treated with increasing doses of morphine for 16 days but the last injection was saline. sal. s.c. saline injection. cort. Blood sampling was taken through tail cut at the time when the last injection was done for plasma corticosterone measurement. decap. Decapitation $4 \mathrm{~h}$ after the last injection.

coefficient of variation was $7 \cdot 5 \%$ and all samples from one experiment were measured in one RIA.

\section{In situ hybridization}

Frozen forebrain and pituitary tissues were mounted on a cryostat microtome and cut into $16 \mu \mathrm{m}$ coronal sections. Every sixth brain section was mounted on a silanized slide, from anterior commissure to the end of the amygdala. Six pituitary sections were put on one slide.

The hybridization technique used was the one described by Simmons (1989) as detailed earlier (Zelena et al. 2006).

\section{CRH $m R N A$}

CRH mRNA levels were quantified by $\left[{ }^{35}\right.$ S]UTP-containing riboprobes complementary to exonic sequences of the $\mathrm{CRH}$ gene (the plasmid containing $1 \cdot 2 \mathrm{~kb}$ template was a generous gift of Dr K Majo, Northwestern University).

After the hybridization process, slides were exposed to imaging plates (Fujifilm, BAS-IP, MS 2340) for $72 \mathrm{~h}$, and the plates were scanned by a fluorescent image analyzer (FLA 3000, Fujifilm, scanning resolution of $50 \mu \mathrm{m}$ ). Radiograms were evaluated by the use of the public domain National Institutes of Health (NIH) Image program (written by Wayne Rasband at NIH and available from the Internet by anonymous ftp from zippy.nimh.nih.gov). The boundary of the examined region was outlined, and the average grayness value was corrected by the background taken from neighboring hypothalamic tissue. Expression of mRNA was evaluated by summing up the grayness values measured over the whole extent of the PVN and amygdala centralis (CeA; integrated density, Barna et al. 2003).

\section{$A V P m R N A$}

AVP mRNA levels were quantified by $\left[{ }^{35} \mathrm{~S}\right] \mathrm{UTP}$-containing riboprobes complementary to the exon sequences of the AVP gene (the plasmid containing the $1.2 \mathrm{~kb}$ template was a generous gift of Dr K Majo, Northwestern University). To determine the AVP mRNA content of the PVN, the hybridized slides were dipped into Kodak NTB3 nuclear emulsion and exposed for 3 days. The microscopic images of the PVN region of the hypothalamus (Fig. 3A) were digitalized by a Sony CCD camera, and the images were stored on CD. Using the NIH Image J1.23 program, the optical density of the silver signal upon a given individual parvocellular cell was determined and the value obtained was corrected for background optical density measured next to the examined parvocellular cell in the same designated frame used for the parvocellular cell. From the PVN region of a given animal, the optical density of about 50-60 parvocellular cells was analyzed on 4-5 hybridized slides (Fig. 3A). The mean optical density of 50-60 parvocellular cells was used as index of AVP activity in the parvocellular region of the PVN in the given experimental animal.

\section{POMC $m R N A$ in the anterior pituitary}

POMC mRNA levels were quantified by riboprobes complementary to the exon sequences of the POMC gene in the presence of $\left[{ }^{35} \mathrm{~S}\right] \mathrm{UTP}$ (the plasmid containing $1.2 \mathrm{~kb}$ template was a generous gift from Dr J Eberwine, University of Pennsylvania). After the hybridization process, the slides were exposed to imaging plates, and the evaluation of the signal intensity was performed similarly as described above for CRH mRNA hybridization. 


\section{Statistical analysis}

Serial blood samples from acute morphine experiment and repeated body weight measurements were analyzed by repeated measures ANOVA. Other data were analyzed by two-way ANOVA. Newman-Keuls test was used for post hoc comparison. All statistical analyses were performed by Statistica 6.0 statistical software (StatSoft Inc., Tulsa, OK, USA). All data are expressed as means \pm s.E.M. The level of significance was set at $P<0 \cdot 05$.

\section{Results}

\section{Acute morphine injection (Exp. 1)}

The manipulation per se (injection and blood sampling) did not induce any ACTH or corticosterone elevation in both genotypes as may be seen in the saline-treated groups (Fig. 1, circles). The administration of a single dose of morphine $(10 \mathrm{mg} / \mathrm{kg})$ profoundly elevated HPA axis hormone levels
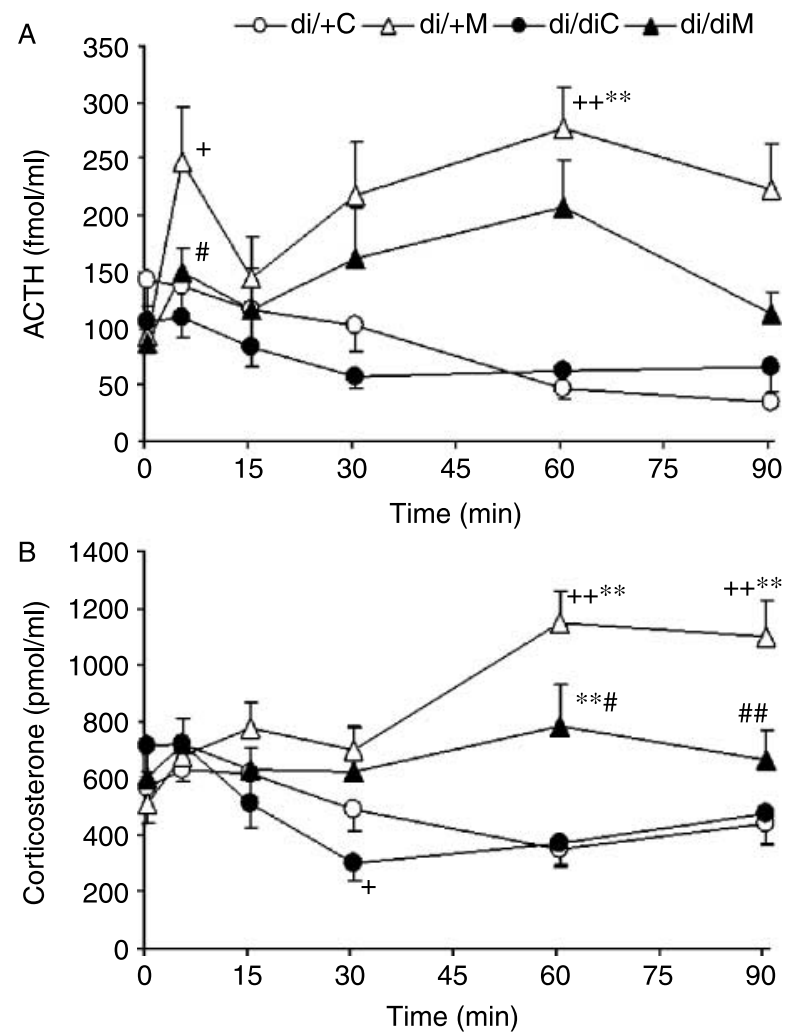

Figure 1 Effect of single morphine injection $(10 \mathrm{mg} / \mathrm{kg}$ per $2 \mathrm{ml}$ saline subcutaneously) on plasma stress hormone levels in AVP-deficient Brattleboro rats $(n=14-18)$. (A) ACTH $(\mathrm{fmol} / \mathrm{ml})$.

(B) Corticosterone $(\mathrm{pmol} / \mathrm{ml})$. Handling was without effect; morphine injection induced a biphasic elevation in both hormone levels with smaller changes in AVP-deficient rats. C, control, salinetreated animals; $M$, morphine treated rats. ${ }^{+} P<0 \cdot 05,{ }^{+}+P<0 \cdot 01$ vs 0 min.; ${ }^{* *} P<0 \cdot 01$ versus saline treated; ${ }^{*} P<0 \cdot 05,{ }^{\# \#} P<0 \cdot 01$ versus respective $\mathrm{di} /+$ group. (effect of treatment: $P<0 \cdot 01$ ) in a biphasic manner demonstrated by significant treatment $X$ time interaction $(P<0 \cdot 01)$. The first ACTH peak was at $5 \mathrm{~min}$, while the second was at $60 \mathrm{~min}$ (approximately threefold elevation in $\mathrm{di} /+)$ with a nadir at $15 \mathrm{~min}$. The corticosterone levels followed the ACTH changes, albeit with smaller, less obvious fluctuation; a clear nadir was present at $30 \mathrm{~min}$ and the corticosterone level showed a second maximum at $60 \mathrm{~min}$ $(\sim 2 \cdot 2$-fold elevation in $\mathrm{di} /+)$ where it remained constant. The absence of AVP in di/di Brattleboro rats led to a small, yet significant reduction in the elevations of both hormones (ACTH, 2-4-fold increase in di/di: effect of genotype: $P=0 \cdot 05$; corticosterone, $1 \cdot 3$-fold increase in di/di: genotype $\times$ time interaction: $P=0 \cdot 049)$.

\section{Chronic morphine treatment (Exp. 2)}

Somatic changes The body weight of the AVP-deficient rats was smaller (initial weight $\mathrm{di} /+: 340 \pm 8 \mathrm{~g}$; di/di: $290 \pm 6 \mathrm{~g})$ throughout the experiment (Fig. 2A; $P<0 \cdot 01$ ).
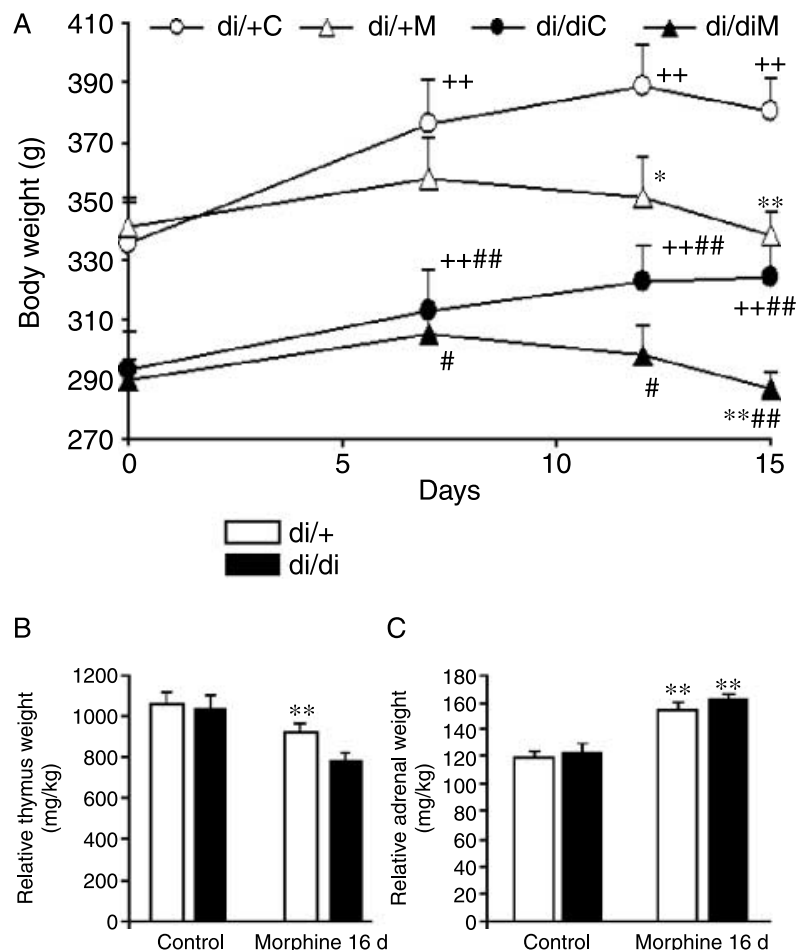

Figure 2 Somatic changes in chronically morphine-treated AVPdeficient Brattleboro rats $(n=18-41)$. (A) The body weight (g) curve during the repeated treatment revealed that the addicted rats did not gain weight. (B) The relative weight of the thymus $(\mathrm{mg} / \mathrm{kg})$ was reduced in repeatedly morphine-treated rats. (C) Adrenal gland $(\mathrm{mg} / \mathrm{kg})$ hypertrophy was clearly visible after repeated morphine injections. The lack of AVP could not prevent any somatic changes induced by repeated morphine treatment, the thymus involution was even more pronounced. ${ }^{++} P<0.01$ versus initial weight; ${ }^{*} P<0 \cdot 05,{ }^{* *} P<0.01$ versus saline treated; ${ }^{\#} P<0 \cdot 05,{ }^{\# \#} P<0.01$ versus respective $\mathrm{di} /+$ group. 
The saline-treated animals of both genotypes gained weight normally (effect of time: $P<0 \cdot 01$ ), while the repeated morphine treatment inhibited the weight gain (treatment $X$ time interaction: $P<0 \cdot 01)$. There was no interaction between the treatment and the genotype suggesting that the body weight reduction was present in both $\mathrm{di} /+$ and $\mathrm{di} / \mathrm{di}$ rats to a similar extent.

As a sign of chronic stress, repeated morphine injections induced thymus involution (Fig. 2B; $P<0 \cdot 01$ ) without genotype effect or treatment $X$ genotype interaction. By pairwise comparison, the AVP deficiency aggravated the reduction of the thymus weight, so surely not prevented the development of this symptom.

Due to enhanced glucocorticoid synthesis adrenal gland hyperplasia was also visible in repeatedly morphine-treated rats (Fig. 2C; $P<0.01$ ) without any effect of genotype or genotype $X$ treatment interaction.

A
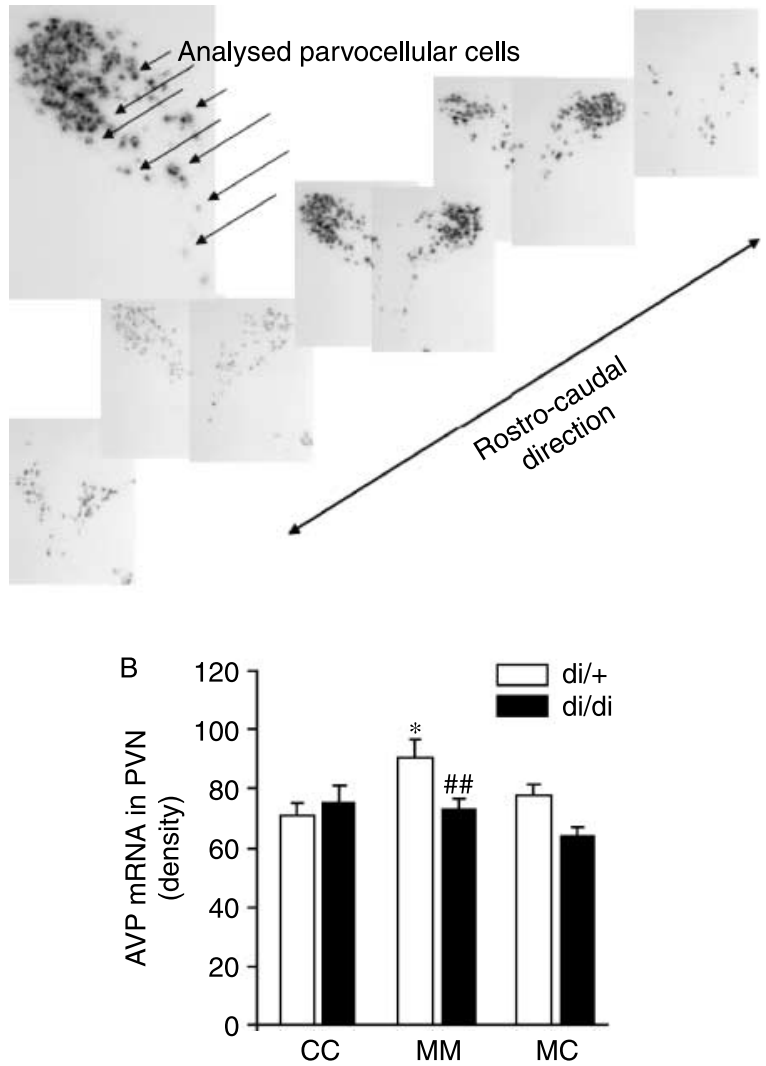

Figure 3 Changes in the AVP mRNA signal above the parvocellular region of the PVN after chronic morphine treatment $(n=5-7)$. (A) Representative slides dipped into emulsion. (B) AVP mRNA levels in the parvocellular part of the PVN (density). The levels were elevated $4 \mathrm{~h}$ after the last morphine injection only in control, $\mathrm{di} /+$ rats. CC, saline treatment; MM, morphine treatment, decapitation $4 \mathrm{~h}$ after the last injection; $\mathrm{MC}$, repeated morphine treatment, only the last injection was saline, i.e., decapitated $16 \mathrm{~h}$ after the last morphine injection. ${ }^{*} P<0.05$ versus saline treated; ${ }^{\# \#} P<0 \cdot 01$ versus respective $\mathrm{di} /+$ group.
Chronic HPA axis changes The AVP mRNA signal overlying parvocellular cells in the PVN (Fig. 3A) was enhanced in repeatedly morphine-treated di/ + animals $4 \mathrm{~h}$ after the last injection (Fig. 3B; MM group; $P=0 \cdot 036$ ), while in the longer withdrawal group (16 $\mathrm{h}$ after the last injection; MC group) the elevation had disappeared. The AVPdeficient rats transcribe measurable amounts of the mutated AVP mRNA, but its regulation failed, and thus it was not changed at any studied time point (effect of genotype: $P=0 \cdot 016$; treatment $\times$ genotype interaction: $P=0 \cdot 036)$.

The intensity of the CRH mRNA signal above the whole PVN was gradually increased in repeatedly morphineinjected groups with a significant rise $16 \mathrm{~h}$ after the last treatment (Fig. 4A; MC group; $P=0 \cdot 048$ ). Higher elevation was induced by the AVP deficiency itself (effect of genotype: $P=0 \cdot 02$ ). In this genotype the morphine treatment did not induce further changes, however, statistically the treatment $X$ genotype interaction was not significant $(P=0 \cdot 083)$.

There was a tendency for higher CRH mRNA level in the amygdala $16 \mathrm{~h}$ after the last injection (MC group; $P=0 \cdot 1$ ), however, a more robust elevation was induced by the AVP deficiency itself (Fig. 4B; $P=0 \cdot 02$ ). The repeated morphine injections reduced the CRH mRNA level in the amygdala of $\mathrm{di} / \mathrm{di}$ rats to the same extent as it was visible in $\mathrm{di} /+$ rats (treatment $\times$ genotype interaction: $P=0 \cdot 01$ ).

Repeated morphine injection significantly elevated the POMC mRNA level in the anterior lobe of the pituitary measurable at both $4 \mathrm{~h}$ (MM group) and $16 \mathrm{~h}$ (MC group) after the last injection (Fig. 4C; $P<0 \cdot 01$ ). Both the basal and stressed levels were the same in control and AVP-deficient animals.

The resting corticosterone level of di/ + rats was elevated by the time the last injection was expected (Fig. 4D; $P<0 \cdot 01)$. However, the saline-treated di/di group had already higher resting levels (effect of genotype: $P<0 \cdot 01$ ), repeated morphine treatment induced a further rise (no treatment $\times$ genotype interaction).

\section{Plasma hormone levels after acute 'withdrawal'}

There was no more than a tendency for ACTH plasma levels to be higher $4 \mathrm{~h}$ after the last morphine injection (MM group; $P=0 \cdot 19)$, but a highly significant increase was observed $16 \mathrm{~h}$ after the last morphine injection (Fig. 5A, MC group, eightfold increase; $P<0 \cdot 01)$. In AVP-deficient rats the elevation was still present however to a lesser extent (fourfold increase; treatment $\times$ genotype interaction: $P=0 \cdot 059)$.

Plasma corticosterone levels were significantly elevated already at $4 \mathrm{~h}$ after the last morphine injection (Fig. 5B, MM group, an approximately $3 \cdot 5$-fold increase; $P<0 \cdot 01)$. The longer 'withdrawal' (MC group, $16 \mathrm{~h}$ after the last injection) showed a more pronounced rise (15-fold; $P<0 \cdot 01)$. In AVP-deficient rats no significant rise was seen at $4 \mathrm{~h}$ 'withdrawal' (MM group; $P=0 \cdot 15)$, while longer 'withdrawal' (MC group; $16 \mathrm{~h}$ ) induced significantly smaller elevations (eightfold; effect of genotype: $P<0 \cdot 01$; treatment $\times$ genotype interaction: $P<0 \cdot 01)$. 

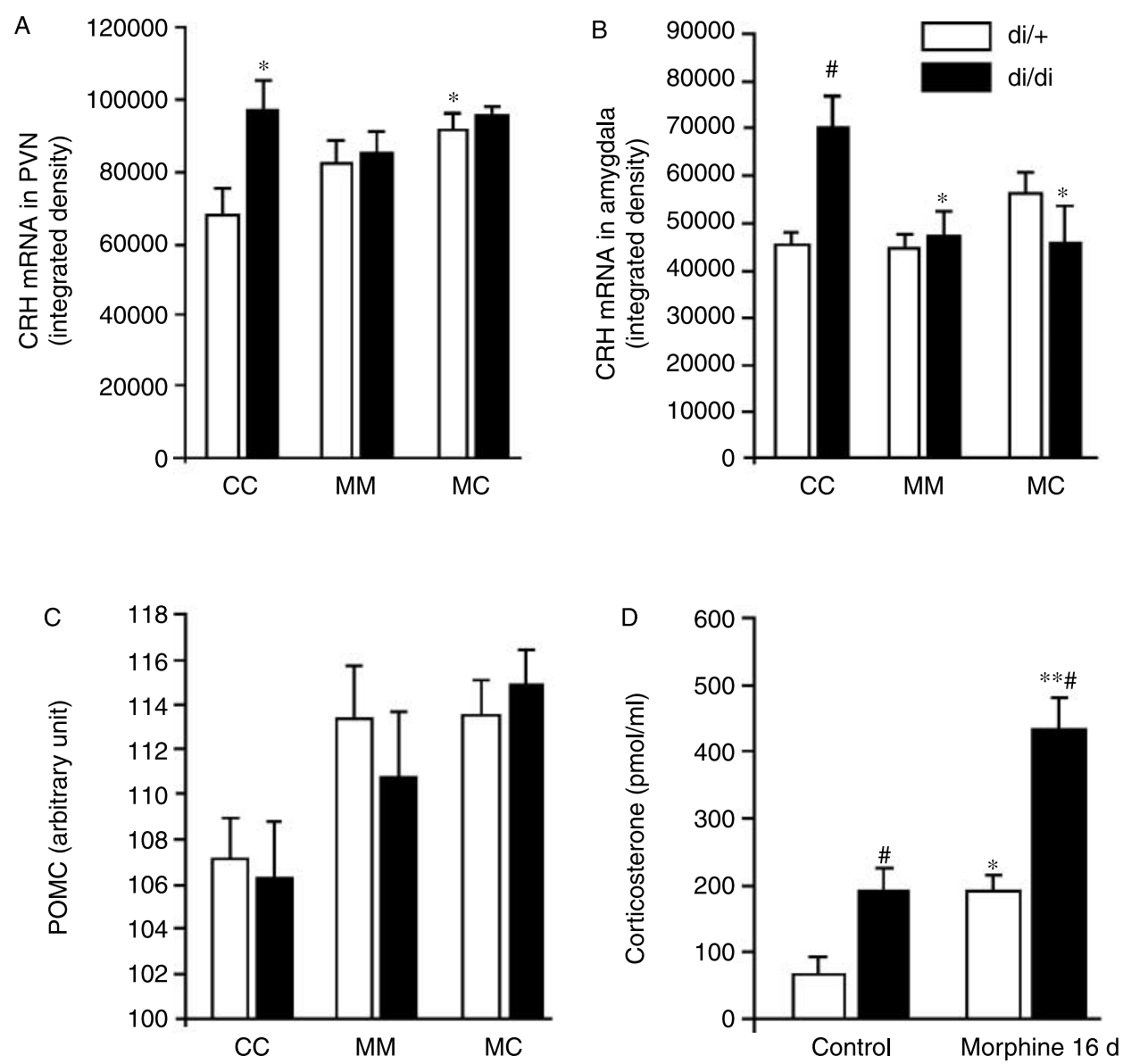

Figure 4 Chronic changes in the HPA axis after repeated morphine injections (A). CRH mRNA level in the PVN (integrated density; $n=5-7$ ). Longer withdrawal stimulated the synthesis in $\mathrm{di} /+$ rats, while in di/di animals the basal levels were already elevated without further reaction. (B) CRH mRNA level in CeA (integrated density; $n=5-7$ ). The AVP deficiency elevated this level but the chronic morphine treatment was able to counteract its effect. (C) POMC mRNA levels in the anterior lobe of the pituitary (arbitrary unit; $n=10-16$ ). Both shorter and longer 'withdrawal' induced a significant rise without any influence of the AVP deficiency. (D) Resting corticosterone levels measured from tail blood at the time last injection expected $(\mathrm{pmol} / \mathrm{ml} ; n=19-40)$. The levels were elevated by repeated morphine treatment but the AVP deficiency per se induced a similar rise with further increase after morphine treatment. CC, saline treatment; MM, morphine treatment, decapitation $4 \mathrm{~h}$ after the last injection; $\mathrm{MC}$, repeated morphine treatment, only the last injection was saline, i.e., decapitated $16 \mathrm{~h}$ after the last morphine injection. ${ }^{*} P<0.05$ versus saline treated; ${ }^{\#} P<0.05$ versus respective $\mathrm{di} /+$ group.

\section{Discussion}

Repeated short periods of morphine withdrawal were associated with chronic activation of the HPA axis and increased the HPA axis activity at all three levels of the axis as it was already partly showed (Houshyar et al. 2001b, 2003, Zelena et al. 2005). Despite the predicted importance of AVP in chronic stress-induced HPA activity (Dallman 1993, Aguilera 1994), its absence in the Brattleboro rat did not prevent chronic stress-induced changes. On the other hand, the acute morphine treatment and withdrawal-induced hormone rises were smaller in these rats lacking AVP.
The ability of single administration of morphine to stimulate the HPA axis in rodents is well known (e.g., Buckingham \& Cooper 1984). In our hands, the single subcutaneous application of a moderate dose of morphine $(10 \mathrm{mg} / \mathrm{kg})$ induced biphasic elevation of ACTH and corticosterone plasma levels. We think that this biphasic reaction was due to different stimulatory aspects of the injection, namely, the first reaction is due to the pain induced by morphine solution, while the second peak demonstrates pharmacological effect of morphine. We were able to demonstrate that s.c. morphine injection has prolonged effect when compared with i.p. injection, while the ACTH rise was 

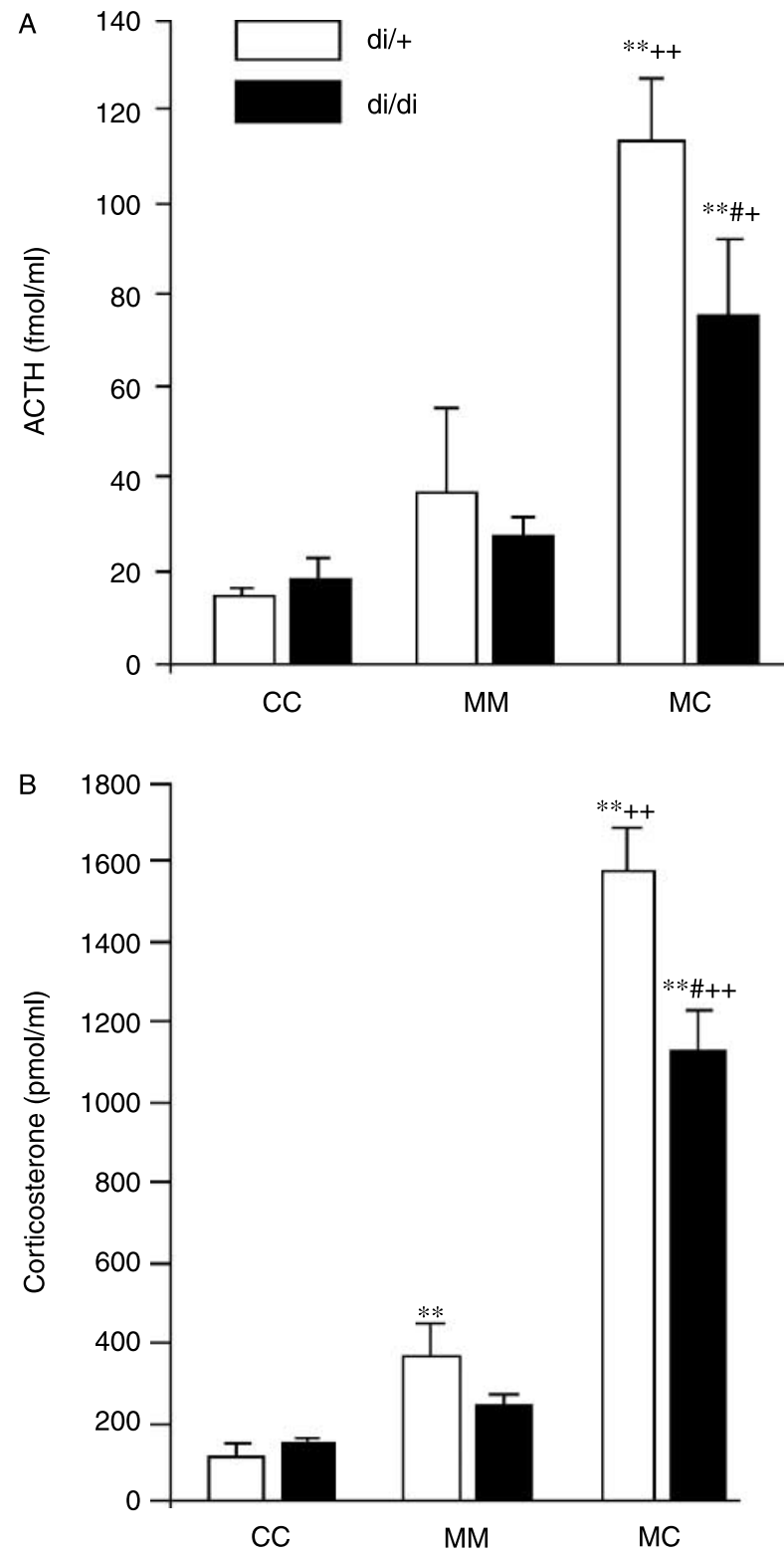

Figure 5 Plasma hormone levels due to acute 'withdrawal' at the end of repeated morphine treatment (A). ACTH ( $\mathrm{fmol} / \mathrm{ml})$ levels were significantly elevated $16 \mathrm{~h}$ after the last morphine injection with a smaller rise in di/di rats $(n=18-23)$. (B) Corticosterone $(\mathrm{pmol} / \mathrm{ml})$ levels were elevated both 4 and $16 \mathrm{~h}$ after the last injection with smaller rises in AVP-deficient rats $(n=18-23)$. CC, saline treatment; MM, morphine treatment, decapitation $4 \mathrm{~h}$ after the last injection; $M C$, repeated morphine treatment, only the last injection was saline, i.e., decapitated $16 \mathrm{~h}$ after the last morphine injection. ${ }^{* *} P<0 \cdot 01$ versus saline treated; ${ }^{*} P<0 \cdot 05$ versus respective $\mathrm{di} /+$ group; ${ }^{+} P<0 \cdot 05 ;^{++} P<0 \cdot 01$ versus MM group.

visible at $60 \mathrm{~min}$. When compared with the similar rise at 5-25 min after an i.p. injection (el Daly 1996). The absence of AVP led to lower stress-hormone levels throughout the whole examination period suggesting that AVP is important but not an exclusive mediator of the opiate-induced HPA axis stimulation. It is worth mentioning that an elevation of the oxytocin levels in $\mathrm{di} / \mathrm{di}$ rats could - at least partly compensate its HPA axis stimulatory role as oxytocin may act on pituitary $\mathrm{V} 1 \mathrm{~b}$ receptors to stimulate $\mathrm{ACTH}$ release (Schlosser et al. 1994).

The role of AVP in opiate-induced acute HPA axis changes was supported further at the end of our chronic studies where we tested the withdrawal-induced hormone changes rather than the effect of repeated morphine administration (Buckingham \& Cooper 1984). The lack of AVP diminished the 'withdrawal'-induced hormone rises in the same manner as in our acute morphine injection studies.

It appears contradictory that AVP-deficient Brattleboro rats transcribe measurable amount of AVP mRNA in their parvocellular PVN cells. It is well known that the homozygous Brattleboro rat transcribes a mutant AVP mRNA from the gene and that its expression is attenuated during development (Van Tol et al. 1986). The sequence of our AVP riboprobe allowed hybridization to the mutated gene. It turned out that the level of the mutated AVP mRNA in the parvocellular PVN is normal although not regulated in $\mathrm{di} / \mathrm{di}$ animals. In control di/ + rats, the amount of AVP mRNA was elevated after shorter $(4 \mathrm{~h})$ morphine withdrawal but not at later time point $(16 \mathrm{~h})$, which is in accordance with our other finding about the role of AVP in short and not in long-term HPA axis regulation. Our findings are supported by the work of Houshyard et al. (2003), who found no AVP mRNA changes in the PVN after prolonged intermittent morphine administration and also by the work of Zhou et al. (2007), who demonstrated that the AVP mRNA levels in the amygdala are elevated only after early heroin withdrawal.

Consistent with the assumption that CRH mRNA in the PVN is often elevated in chronic stress (Aguilera 1994), we detected increased levels in morphine-dependent control $(\mathrm{di} /+)$ rats $16 \mathrm{~h}$ after the last injection. The shorter period of 'withdrawal' (4h) did not induce significant changes (Lightman \& Young 1988) suggesting that CRH has a regulatory role in prolonged rather than acute HPA axis changes. As the AVP-deficient rats had elevated basal CRH mRNA levels - probably due to a compensatory mechanism - we cannot conclude that the lack of elevation in this genotype was due to a regulatory role of AVP or resting levels was already at maximum and further elevation was not possible.

The action of opioids on HPA axis activity has been postulated to involve extra-hypothalamic mediators (Coventry et al. 2001). The central nucleus of the amygdala (CeA) may be an important site during opioid withdrawal as it is rich in cells producing the opioid and AVP system (Zhou et al. 2007) and a functional interaction between the opioidergic and CRHergic systems has also been postulated (Maldonado et al. 1992). In contrast, we could not find a significant CRH mRNA elevation in the central nucleus of amygdala of morphine-treated rats (similarly to Houshyard et al. 2003). On the other hand, we could demonstrate the inhibitory opioid tone on the amygdala 
CRH expression (McNally \& Akil 2002) in AVP-deficient rats with elevated resting levels.

Gene expression of POMC, the precursor of ACTH in the anterior pituitary, increases slowly after sustained stimulation, and thus it can reflect long-term changes as it did in morphine (Hollt \& Haarmann 1985) or heroin (Zhou et al. 2007) dependent rats. In our hand, both the 4 and $16 \mathrm{~h}$ withdrawal induces similar elevations and the AVP deficiency was unable to influence the basal as well as the stressed levels.

The synthesis of glucocorticoids may be enhanced after repeated stimulation. Consequently, adrenal cortex hypertrophy, elevated resting plasma corticosterone level, and thymus involution together with body weight reduction appear the best parameters of chronic stress (e.g., Zelena et al. 2005) as shown here in our study with morphine-dependent rats. Thus, we could demonstrate that intermittent morphine treatment induced a chronic stress-like state (Houshyard et al. 2003, Zelena et al. 2005). However, we have to reject one of our hypotheses as AVP deficiency did not moderate the morphine dependence-induced changes. The di/di rats are smaller and likely to be chronically stressed even among basal conditions and it could prevent further development of chronic stress symptoms. In contrast, the lack of AVP even aggravated the thymus involution.

Our data do suggest that AVP plays a prominent role in acute morphine treatment and withdrawal-induced hormone changes without affecting the development of the chronic hyperactivity of the HPA axis, thus its role in the development of dependence is questionable; it may be more important in withdrawal-induced symptoms.

\section{Acknowledgements}

The authors are grateful to the Hormone Laboratory for the RIA measurements and H Bekőné for the technical assistance. This work was supported by OTKA T 043161 and F 048783 grants. There is no conflict of interest.

\section{References}

Aguilera G 1994 Regulation of pituitary ACTH secretion during chronic stress. Frontiers in Neuroendocrinology 15 321-350.

Antelman SM, Eichler AJ, Black CA \& Kocan D 1980 Interchangeability of stress and amphetamine in sensitization. Science 207 329-331.

Antoni FA 1993 Vasopressinergic control of pituitary adrenocorticotropin secretion comes of age. Frontiers in Neuroendocrinology 14 76-122.

Barna I, Bálint E, Baranyi J, Bakos N, Makara GB \& Haller J 2003 Genderspecific effect of maternal deprivation on anxiety and corticotropinreleasing hormone mRNA expression in rats. Brain Research Bulletin 62 85-91.

Bohus B \& de Wied D 1998 The vasopressin deficient brattleboro rats: a natural knockout model used in the search for CNS effects of vasopressin. Progress in Brain Research 119 555-573.

Breese GR, Knapp DJ \& Overstreet DH 2004 Stress sensitization of ethanol withdrawal-induced reduction in social interaction: inhibition by CRF-1 and benzodiazepine receptor antagonists and a 5-HT1A-receptor agonist. Neuropsychopharmacology 29 470-482.
Briggs FN \& Munson PL 1955 Studies on the mechanism of stimulation of ACTH secretion with the aid of morphine as a blocking agent. Endocrinology 57 205-219.

Buckingham JC 1982 Secretion of corticotrophin and its hypothalamic releasing factor in response to morphine and opioid peptides. Neuroendocrinology 35 111-116.

Buckingham JC \& Cooper TA 1984 Differences in hypothalamo-pituitaryadrenocortical activity in the rat after acute and prolonged treatment with morphine. Neuroendocrinology 38 411-417.

Buckingham JC \& Cooper TA 1986a Effects of naloxone on hypothalamopituitary-adrenocortical activity in the rat. Neuroendocrinology 42 421-426.

Buckingham JC \& Cooper TA $1986 b$ Pharmacological characterization of opioid receptors influencing the secretion of corticotrophin releasing factor in the rat. Neuroendocrinology $4436-40$.

Coventry TL, Jessop DS, Finn DP, Crabb MD, Kinoshita H \& Harbuz MS 2001 Endomorphins and activation of the hypothalamo-pituitary-adrenal axis. Journal of Endocrinology 169 185-193.

Dallman MF 1993 Stress update. adaptation of the hypothalamic-pituitaryadrenal axis to chronic stress. Trends in Endocrinology and Metabolism 4 62-69.

el Daly ES 1996 Influence of acute and chronic morphine or stadol on the secretion of adrenocorticotrophin and its hypothalamic releasing hormone in the rat. Life Sciences 59 1881-1890.

Deroche V, Piazza PV, Casolini P, Maccari S, Le Moal M \& Simon H 1992 Stress-induced sensitization to amphetamine and morphine psychomotor effects depend on stress-induced corticosterone secretion. Brain Research $598343-348$.

Hollt V \& Haarmann I 1985 Differential alterations by chronic treatment with morphine of pro-opiomelanocortin mRNA levels in anterior as compared to intermediate pituitary lobes of rats. Neuropeptides $\mathbf{5} 481-484$.

Houshyar H, Cooper ZD \& Woods JH 2001a Paradoxical effects of chronic morphine treatment on the temperature and pituitary-adrenal responses to acute restraint stress: a chronic stress paradigm. Journal of Neuroendocrinology 13 862-874.

Houshyar H, Galigniana MD, Pratt WB \& Woods JH $2001 b$ Differential responsivity of the hypothalamic-pituitary-adrenal axis to glucocorticoid negative-feedback and corticotropin releasing hormone in rats undergoing morphine withdrawal: possible mechanisms involved in facilitated and attenuated stress responses. Journal of Neuroendocrinology 13 875-886.

Houshyar H, Gomez F, Manalo S, Bhargava A \& Dallman MF 2003 Intermittent morphine administration induces dependence and is a chronic stressor in rats. Neuropsychopharmacology 28 1960-1972.

Ignar DM \& Kuhn CM 1990 Effects of specific mu and kappa opiate tolerance and abstinence on hypothalamo-pituitary-adrenal axis secretion in the rat. Journal of Pharmacology and Experimental Therapeutics 255 1287-1295.

Lightman SL \& Young WS, III 1988 Corticotrophin-releasing factor, vasopressin and pro-opiomelanocortin mRNA responses to stress and opiates in the rat. Journal of Physiology 403 511-523.

Maldonado R, Stinus L, Gold LH \& Koob GF 1992 Role of different brain structures in the expression of the physical morphine withdrawal syndrome. Journal of Pharmacology and Experimental Therapentics 261 669-677.

McNally GP \& Akil H 2002 Role of corticotropin-releasing hormone in the amygdala and bed nucleus of the stria terminalis in the behavioral, pain modulatory, and endocrine consequences of opiate withdrawal. Neuroscience 112 605-617.

Schlosser SF, Almeida OF, Patchev VK, Yassouridis A \& Elands J 1994 Oxytocin-stimulated release of adrenocorticotropin from the rat pituitary is mediated by arginine vasopressin receptors of the V1b type. Endocrinology 135 2058-2063.

Schmale H \& Richter D 1984 Single base deletion in the vasopressin gene is the cause of diabetes insipidus in Brattleboro rats. Nature 308 705-709.

Simmons A 1989 Complete protocol for in situ hybridization of messenger RNAs in brain and other tissues with radiolabeled single-stranded RNA probes. Journal of Histotechnology 12 169-181.

Van Tol HH, Voorhuis TA, Snijdewint FG, Boer GJ \& Burbach JP 1986 Vasopressin gene expression is attenuated in the fetal Brattleboro rat. FEBS Letters 204 101-105. 
Tribollet E, Barberis C, Jard S, Dubois-Dauphin M \& Dreifuss JJ 1988 Localization and pharmacological characterization of high affinity binding sites for vasopressin and oxytocin in the rat brain by light microscopic autoradiography. Brain Research 442 105-118.

Zelena D, Kiem DT, Barna I \& Makara GB 1999 Alpha 2-adrenoreceptor subtypes regulate $\mathrm{ACTH}$ and beta-endorphin secretions during stress in the rat. Psychoneuroendocrinology 24 333-343.

Zelena D, Mergl Z, Foldes A, Kovacs KJ, Toth Z \& Makara GB 2003a Role of hypothalamic inputs in maintaining pituitary-adrenal responsiveness in repeated restraint. American Journal of Physiology. Endocrinology and Metabolism 285 E1110-E1117.

Zelena D, Mergl Z \& Makara GB 2003b Maternal genotype influences stress reactivity of vasopressin-deficient brattleboro rats. Journal of Neuroendocrinology 15 1105-1110.

Zelena D, Barna I, Mlynarik M, Gupta OP, Jezova D \& Makara GB 2005 Stress symptoms induced by repeated morphine withdrawal in comparison to other chronic stress models in mice. Neuroendocrinology 81 205-215.
Zelena D, Filaretova L, Mergl Z, Barna I, Toth ZE \& Makara GB 2006 Hypothalamic paraventricular nucleus, but not vasopressin, participates in chronic hyperactivity of the HPA axis in diabetic rats. American Journal of Physiology. Endocrinology and Metabolism 290 E243-E250.

Zhou Y, Leri F, Cummins E, Hoeschele M \& Kreek MJ 2007 Involvement of arginine vasopressin and $\mathrm{V} 1 \mathrm{~b}$ receptor in heroin withdrawal and heroin seeking precipitated by stress and by heroin. Neuropsychopharmacology In press.

Received in final form 24 September 2007

Accepted 16 October 2007

Made available online as an Accepted Preprint 16 October 2007 